\title{
Komposisi dan Keanekaragaman Jenis Pohon di Hutan Lindung Lapeom Kabupaten Timor Tengah Utara
}

\author{
Yolanda G. Naisumua, Yoseph N. Seran ${ }^{\mathrm{b}}$, Ludgardis Ledheng ${ }^{\mathrm{c}}$ \\ ${ }^{a}$ Program Studi Biologi, Universitas Timor, Kefamenanu, TTU - NTT, Indonesia \\ b Program Studi Pendidikan Biologi, Universitas Timor, Kefamenanu, TTU - NTT, Indonesia \\ c Program Studi Pendidikan Biologi, Universitas Timor, Kefamenanu, TTU - NTT, Indonesia
}

\section{Article Info}

\section{Article history:}

Received 8 Mei 2018

Received in revised form 19 Juni 2018

Accepted 5 Juli 2018

\section{DOI: \\ https://doi.org/10.32938/slk.v1i1.406}

\section{Keywords:}

Komposisi

Keanekaragaman Jenis

Pohon

Hutan Lindung Lapeom

\section{Abstrak}

Penelitian ini bertujuan untuk mendeskripsikan komposisi dan keanekaragaman jenis pohon di Hutan Lindung Lapeom. Penelitian dilaksanakan pada bulan November sampai Desember 2009 menggunakan metode kuadrat dengan menempatkan plot di sepanjang garis transek. Jumlah transek 5 buah, panjang transek $200 \mathrm{~m}$, di setiap transek diletakkan 5 plot pengamatan dengan ukuran $20 \mathrm{~m}$ x $20 \mathrm{~m}$. Hasil penelitian menunjukkan bahwa di lokasi penelitian ditemukan 22 jenis pohon dari 17 famili. Jumlah spesies lebih dari 10 menunjukkan bahwa tumbuhan yang terdapat pada Hutan Lindung Lapeom Desa Lapeom bervariasi. Famili dengan jumlah spesies terbanyak adalah famili Caesalpinaceae sebanyak 4 spesies yakni Cassia fistula L., Delonix regia (Bojer ex Hook.) Raf., Senna simea (Lam.) Irwin \& Barneby., dan Tamarindus indica L. Jenis dengan jumlah individu terbanyak adalah Mangifera indica L dari famili Anacardiaceae sebanyak 20 individu. Spesies dengan indeks nilai penting tertinggi adalah Mangifera indica L $(43,7 \%)$, sedangkan jenis yang memiliki indeks nilai penting terendah adalah Zizipus jujuba $(1,8 \%$,) dan Jatropa sp. 1,9\%). Indeks Keanekaragaman jenis pohon di Hutan Lindung Lapeom termasuk kategori sedang dengan nilai 2,7 hal ini menunjukkan bahwa wilayah hutan lindung lapeom merupakan wilayah yang memiliki tingkat produktivitas pohon yang cukup, kondisi ekosistem yang cukup seimbang dan memiliki tekanan ekologis sedang. Dari hasil penelitian dapat disimpulkan komposisi jenis Pohon di Hutan Lindung Lapeom sebanyak 22 pohon dalam 17 famili. Jenis yang paling banyak jumlah individunya adalah Mangifera indica L dari famili Anacardiaceae. Spesies yang memiliki indeks nilai penting tertinggi adalah Mangifera indica L (43,7\%) dan jenis yang memiliki indeks nilai penting terendah adalah Zizipus jujuba (1,8\%), Indeks Keanekaragaman jenis pohon di hutan lindung Lapeom termasuk kategori sedang.

\section{Pendahuluan}

Hutan merupakan suatu komunitas tumbuhan dari berbagai tipe vegetas yang hidup bersama-sama di suatu wilayah yang memperlihatkan pola distribusi menurut ruang (Spatial) dan waktu (Temporal) (Mueller-Dombois \& Ellenberg, 1974; Indriyanto, 2006). Hutan merupakan kombinasi antara jenis-jenis yang ada dan kemelimpahan relatifnya yang menjadi pendukung aktivitas hutan dalam hal penyediaan nitrogen, oksigen, karbon dan lainnya. Tumbuhan yang tumbuh di hutan sangat beraneka ragam jenisnya tergantung pada kondisi lingkungan di wilayah itu.

Arief (2001) mengemukakan bahwa Indonesia memiliki luas hutan yang berdasarkan tata guna hutan kesepakatan (TGHK) adalah 140,4 juta ha. yang terdiri atas kawasan hutan tetap adalah 26,6 juta ha, hutan suaka alam dan hutan wisata seluas 18,8 juta ha, hutan produksi adalah 64,3 juta ha dan hutan yang fungsinya penelitian, pendidikan dan pusat latihan gajah atau satwa lainnya belum terukur. Dari luas hutan Indonesia berdasarkan TGHK sebagiannya merupakan luas hutan provinsi Nusa Tenggara Timur terutama kabupaten Timor Tengah Utara.

Kabupaten Timor Tengah Utara (TTU) memiliki luas lahan sebesar 266,976 ha; sebagian lahan ditutupi oleh hutan sebesar 126,36 ha $(47,25 \%)$ hutan produksi tetap seluas 1.566 ha $(1,23 \%)$, hutan produksi terbatas $68,068 \%$ $(53,83 \%)$ hutan produksi yang dapat dikonversi seluas 13.524 ha $(10,67 \%)$, hutan cagar alam atau suaka margasatwa seluas $2.000 \mathrm{Ha}$ (1,59\%) (BPS TTU, 2007).

Hutan Lapeom merupakan salah satu komunitas hutan lindung di Kabupaten Timor Tengah Utara yang terletak di Desa Lapeom Kecamatan Insana Barat yang memiliki luas 16 ha. Hutan Lapeom memiliki keanekaragaman flora dan fauna yang dilindungi. Mengingat status hutan Lapeom sebagai Hutan Lindung maka perlu adanya penelitian yang spesifik mengkaji tentang komposisi jenis dalam hal ini susunan tumbuhan dan jumlah dari setiap jenis tumbuhan yang terdapat di dalam hutan lindung Lapeom. Selain komposisi jenis, hal yang tidak kalah penting untuk diketahui dalam suatu komunitas adalah indeks nilai penting (INP) dan keanekaragaman jenis pohon yang terdapat di hutan Lapeom. Indeks nilai penting menunjukkan kepentingan suatu jenis tumbuhan serta peranannya dalam komunitas sedangkan keanekaragaman jenis menunjukkan variasi jenis atau jumlah jenis dalam satu komunitas. Dengan mengetahui komposisi, indeks nilai penting (INP) dan keanekaragaman jenis pohon di dalam hutan lindung Lapeom maka kita dapat mengetahui struktur tumbuhan suatu komunitas Hutan Lindung Lapeom (Soegianto, 1994) sehingga pemerintah dapat dengan mudah untuk mengambil kebijakan mengenai hutan Lapeom dan dapat memanfaatkan hasil hutan sesuai dengan kebutuhan masyarakat daerah setempat dengan melihat pada status hutan tersebut sebagai hutan lindung. Penelitian ini bertujuan untuk mendeskripsikan komposisi jenis, keanekaragaman spesies tingkat pohon di Hutan Lindung Lapeom.

\section{Metode}

\subsection{Waktu dan Tempat}

Penelitian ini dilaksanakan pada bulan November sampai Desember 2009 di kawasan hutan lindung Lapeom Desa Lapeom Kecamatan Insana Barat Kabupaten Timor Tengah Utara.

\subsection{Rancangan penelitian}

Penelitian ini mengkaji tentang komposisi jenis, indeks nilai penting dan keanekaragaman jenis tingkat pohon. Analisis struktur tegakan tingkat pohon menggunakan metode kuadrat dengan menempatkan plot di sepanjang garis transek atau menempatkan petak di sepanjang garis (Indriyanto, 2006). Jumlah transek 5 buah. Panjang garis transek $200 \mathrm{~m}$, jarak antar transek $50 \mathrm{~m}$. pada setiap transek diletakkan plot pengamatan sebanyak 5 buah dengan ukuran plot $20 \mathrm{~m} \mathrm{x}$
20 m (Indriyanto, 2006; Sulistyawati $d k k$. , 2005) sehingga jumlah plot pengamatan adalah 25, dan jarak antar plot $25 \mathrm{~m}$.

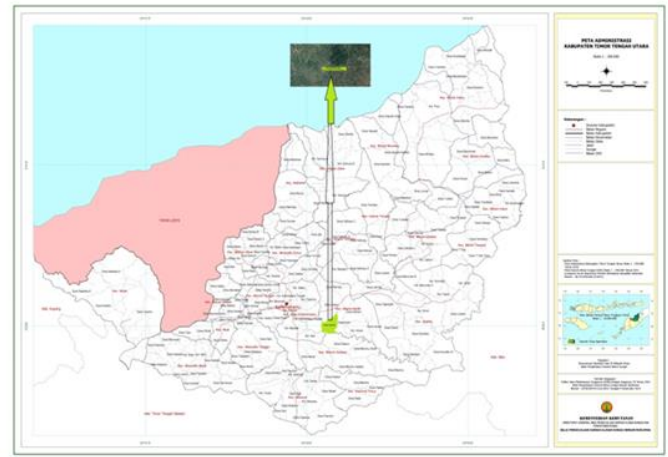

Gambar 1. Lokasi Penelitian, Hutan Lindung Lapeom, Desa Lapeom Kabupaten Timor tengah Utara

\subsection{Alat dan Bahan}

Alat dan bahan yang dibutuhkan dalam penelitian ini adalah Kompos untuk pemetaan lokasi, Roll meter untuk mengukur daerah penelitian dalam hal ini panjang transek dan plot, Kayu patok sebagai patokan dalam membuat transek dan plot, Tali rafia untuk menarik garis transek dan plot serta membatasi daerah penelitian, Parang atau pisau untuk memotong kayu patok, $\mathrm{pH}$ meter untuk mengukur $\mathrm{pH}$ tanah, Thermohygrometer untuk mengukur suhu dan kelembaban, Med-line untuk mengukur keliling batang, kantong plastik sebagai wadah untuk menampung spesies yang belum diketahui, kertas label untuk menandai spesies yang diteliti, alat tulis berfungsi untuk menulis data di lokasi dan Log book berfungsi untuk mencatat data di lapangan.

\subsection{Prosedur kerja}

Menentukan batas daerah penelitian dengan menggunakan kompos, membuat garis transek dengan menggunakan tali rafia dan kayu patok, panjang transek $200 \mathrm{~m}$ dan jumlah transek 5 buah, jarak antar transek $50 \mathrm{~m}$. Meletakkan plot-plot pengamatan di sepanjang garis transek dengan ukuran plot $20 \mathrm{~m}$ x 20 $\mathrm{m}$. setiap transek diletakkan 5 plot pengamatan. Pengamatan terhadap setiap jenis tanaman, komposisi jenis dan keanekaragaman jenis pohon dilakukan di dalam plot pengamatan yang berukuran $20 \mathrm{~m}$ x $20 \mathrm{~m}$. Semua jenis pohon yang ditemui pada setiap plot dicatat sebagai data mentah untuk analisis data.

\subsection{Strategi Analisis Data}

Kajian Struktur Vegetasi

Penentuan struktur vegetasi didasarkan pada distribusi individu dan basa area tegakan pada berbagai kelas diameter. Pengukuran dilakukan dengan mengukur diameter batang setinggi dada $(150 \mathrm{~cm})$ atau $50 \mathrm{~cm}$ di atas akar papan untuk tegakan tingkat pohon yang mempunyai akar papan (Setiadi \& Tjondronegoro, 1989).

Penentuan diameter batang dengan mengonversikan keliling batang yang telah diukur degan rumus:

$$
\mathrm{d}=\frac{\text { Keliling batang }}{\pi}
$$

Deskripsi suatu komunitas tumbuhan diperlukan minimal tiga macam parameter kualitatif antara lain densitas, frekuensi dan dominasi (Gopal \& Bhardwaj, 1979) yang hasilnya dinyatakan dalam bentuk Indeks nilai penting. 
Penentuan Indeks Nilai Penting (INP) dihitung dengan menggunakan rumus sebagai berikut (Hardjosuwarno, 1990) :

\section{Kerapatan (Densitas)}

Kerapatan (Densitas) adalah jumlah individu persatuan luas yang dinyatakan dalam $\mathrm{m} 2$ atau ha ditulis dalam rumus sebagai berikut :

$$
K M=\frac{\sum \text { Individu Suatu jenis }}{\text { Luas Total Plott Pengamatan }}
$$

Kerapatan relatif adalah densitas suatu spesies sebagai presentasi densitas total. Ditulis dalam rumus sebagai berikut :

$$
\mathrm{KR}=\frac{\mathrm{KM} \text { suatu jenis }}{\mathrm{KM} \text { semua Jenis }} \times 100 \%
$$

Frekuensi

Frekuensi adalah presentasi hadirnya suatu spesies dalam plot pengamatan per jumlah semua plot pengamatan. Rumusnya sebagai berikut :

$$
F M=\frac{\sum \text { Plot terdapatnya suatu spesies }}{\sum \text { Plot pengamatan }}
$$

Frekuensi relatif adalah frekuensi spesies sebagai persentase total tumbuhan. Rumusnya sebagai berikut

$$
F R=\frac{\text { Frekuensi Suatu Spesies }}{\text { Frekuensi semua spesies }} \times 100 \%
$$

\section{Dominasi dinyatakan dalam basal area (Basal area)}

Besaran yang digunakan untuk menyatakan derajat penguasaan ruang atau tempat tumbuh berupa luas area yang ditumbuhi oleh sejenis tumbuhan. Salah satu bagian yang harus diukur dalam perhitungan dominasi adalah basal area (basal over) (Kusmana, 1997) dengan rumus sebagai berikut:

Luas area basal total suatu spesies $=\Sigma$ area basal suatu jenis

$$
D M=\frac{\text { Luas basal area }}{\text { Luas Total Plot Pengamatan }}
$$

$$
D R(\%)=\frac{\sum \text { Dominasi Suatu Jenis }}{\sum \text { dominasi Semua Jenis }} \times 100 \%
$$

\section{Indeks Nilai penting (INP)}

Indeks nilai penting (INP) adalah parameter kuantitatif yang dapat dipakai untuk menyatakan tingkat dominasi (tingkat penguasaan) spesies-spesies dalam komunitas tumbuhan (Indriyanto, 2006). Indeks nilai penting diperoleh dari penjumlahan densitas relatif, frekuensi relatif dan luas area basal relatif (Dominansi relatif) (LAB/DR), dimana :

$$
\mathrm{INP}=\mathrm{KR}+\mathrm{FR}+\mathrm{DR}
$$

Keanekaragaman Jenis

Keanekaragaman jenis akan dinyatakan dalam indeks Shannon (H') yang dihitung menggunakan rumus sebagai berikut :

$$
\mathrm{H}^{\prime}=-\Sigma \text { pi Ln pi }
$$

dimana pi adalah proporsi jumlah individu jenis ke-i terhadap jumlah individu total (Stiling, 2014).

\section{Hasil dan Pembahasan}

Berdasarkan penelitian yang dilakukan di hutan lindung Lapeom, desa Lapeom kecamatan Insana barat, Kabupaten Timor Tengah Utara, diperoleh hasil sebagai berikut

\subsection{Komposisi jenis}

Berdasarkan Penelitian yang telah dilakukan, hasil identifikasi jenis dan suku tumbuhan khususnya tegakan tingkat pohon berdiameter $\geq 10 \mathrm{~cm}$ di hutan lindung Lapeom disajikan pada Tabel 1.

Berdasarkan Tabel 1. tegakan tingkat pohon di Hutan Lindung Lapeom terdiri dari 22 spesies tumbuhan, terbagi dalam 17 famili. Famili yang memiliki jumlah spesies terbanyak adalah famili Caesalpinaceae sebanyak 4 spesies yakni Cassia fistula L., Delonix regia (Bojer ex Hook.)Raf., Senna simea (Lam) Irwindy \& barneby., dan Tamarindus indica L. Famili dengan jumlah spesies terbanyak kedua adalah Bombaceae yang terdiri dari Bombax ceiba L dan Bombax valletonii Hochr dan famili Aceraceae yang terdiri dari Acer niveum $\mathrm{BL}$

\begin{tabular}{|c|c|c|c|c|}
\hline No & Nama Lokal & Nama Ilmiah & Famili (suku) & $\sum$ in \\
\hline 1 & Cemara & Casuarina junghuniana Mia & Casuarinaceae & 4 \\
\hline 2 & Beringin & Ficus benjamina $\mathrm{L}$ & Moraceae & 5 \\
\hline 3 & Sublele & Psidium Eugenia L & Myrtaceae & 17 \\
\hline 4 & Haumina & Acer niveum $\mathrm{BL}$ & Aceraceae & 19 \\
\hline 5 & Kusambi & Schleisera okosa Merr & Sapindaceae & 3 \\
\hline 6 & Nitas & Bombax ceiba $\mathrm{L}$ & Bombaceae & 17 \\
\hline 7 & Nikis & Cassia fistula $L$ & Caesalpiniaceae & 8 \\
\hline 8 & Lete & Alstonia scholaris $\mathrm{R} . \mathrm{Br}$ & Apocynaceae & 4 \\
\hline 9 & Pakuplo & Jatropa $\mathrm{Sp}$ & Euphorbiaceae & 1 \\
\hline 10 & At,anonak & Anona reticulata $\mathrm{L}$ & Anonaceae & 4 \\
\hline 11 & $\begin{array}{l}\text { Mangga } \\
\text { hutan }\end{array}$ & Mangifera indica $\mathrm{L}$ & Anacardiaceae & 20 \\
\hline 12 & Hautimu & Timonius amboinicus Boerl & Rubiaceae & 5 \\
\hline 13 & Psinit & $\begin{array}{l}\text { Delonix regia (Bojer ex } \\
\text { Hook.)Raf. }\end{array}$ & Caesalpiniaceae & 6 \\
\hline 14 & Haubesi & Acasia auriculiaformis A. cun & Mimosaceae & 7 \\
\hline 15 & Ketapang & Terminalia cattapa & Combretaceae & 6 \\
\hline 16 & Johar & $\begin{array}{l}\text { Senna simea (Lam.) Irwindy } \\
\text { \& Barneby }\end{array}$ & Caesalpiniaceae & 3 \\
\hline 17 & Nunbai & Cordia subpubensens & Boraginaceae & 3 \\
\hline 18 & Kapok hutan & Bombax valletonii Hochr & Bombaceae & 1 \\
\hline 19 & Kabuka & Zizipus jujuba Mill & Rhamnaceae & 1 \\
\hline 20 & Haubifo & Nephelium $\mathrm{Sp}$ & Channdaceae & 3 \\
\hline 21 & Asam & Tamarindus indica $\mathrm{L}$ & Caesalpiniaceae & 1 \\
\hline 22 & Haumael & Amorphopalus Sp & Aceraceae & 1 \\
\hline
\end{tabular}
dan Amorphopalus Sp. Jumlah spesies lebih dari 10 ini menunjukkan bahwa tumbuhan yang terdapat pada Hutan Lindung Lapeom Desa Lapeom bervariasi.
Jenis tumbuhan yang bervariasi ini disebabkan karena hutan ini merupakan salah satu hutan yang dilindungi sehingga jumlah jenisnya dapat dipertahankan bahkan bisa meningkat dalam beberapa tahun kedepan jika hutan Lapeom tersebut bisa dipertahankan dan dijaga agar tetap berstatus sebagai Hutan Lindung.

Tabel 1. Komposisi Jenis dan Famili tegakan tingkat pohon di Hutan Lindung

Tabel 1. juga menunjukkan Jenis yang paling banyak jumlah individunya adalah Mangifera indica L dari famili Anacardiaceae sebanyak 20 individu, selanjutnya diikuti oleh Acer niveum BL sebanyak 19 individu, Psidium Eugenia L dan Bombax ceiba L masing-masing sebanyak 17 individu sedangkan jenis lainnya memiliki jumlah individu kurang dari 10 individu. Jumlah individu terbanyak merupakan spesies paling banyak hadir di suatu wilayah. Spesies yang paling banyak hadir menunjukkan bahwa spesies tersebut merupakan spesies yang paling mendominasi di wilayah tersebut. Kehadiran suatu jenis pohon pada daerah tertentu menunjukkan kemampuan pohon tersebut untuk beradaptasi dengan kondisi lingkungan setempat, sehingga spesies Mangifera indica L yang mendominasi di area penelitian merupakan jenis yang memiliki kemampuan untuk beradaptasi dan toleransi dengan kondisi lingkungan.

\begin{tabular}{|c|c|c|c|c|}
\hline No Nama Jenis/Spesies & $\mathrm{KR}(\%)$ & FR $(\%)$ & $\mathrm{DR}(\%)$ & $\operatorname{INP}(\%)$ \\
\hline 1 Casuarina junghuniana Mia & 2,88 & 3,2 & 3,26673 & 9,336 \\
\hline Ficus benjamina $\mathrm{L}$ & 3,6 & 5,3 & 3,1968 & 12,11 \\
\hline Psidium Eugenia $\mathrm{L}$ & 12,2 & 13 & 15,3669 & 40,36 \\
\hline Acer niveum $\mathrm{BL}$ & 13,7 & 9,6 & 8,78107 & 32,02 \\
\hline Schleisera okosa Merr & 2,16 & 3,2 & 0,84399 & 6,194 \\
\hline Bombax ceiba $\mathrm{L}$ & 12,2 & 12 & 8,77905 & 32,71 \\
\hline Cassia fistula, $\mathrm{L}$ & 5,76 & 5,3 & 3,50696 & 14,58 \\
\hline $8 \quad$ Alstonia scholaris $\mathrm{R}, \mathrm{Br}$ & 2,88 & 4,3 & 0,49431 & 7,627 \\
\hline $9 \quad$ Jatropa $\mathrm{Sp}$ & 0,72 & 1,1 & 0,09311 & 1,876 \\
\hline 10 Anona reticulata $\mathrm{L}$ & 2,88 & 4,3 & 0,39594 & 7,529 \\
\hline 11 Mangifera indica $\mathrm{L}$ & 14,4 & 11 & 18,682 & 43,71 \\
\hline 12 Timonius amboinicus, Boerl & 3,6 & 5,3 & 0,53495 & 9,451 \\
\hline 13 Delonix regia, (Bojer ex Hook,)Raf, & 4,32 & 4,3 & 6,25035 & 14,82 \\
\hline 14 Acasia auriculiaformis, A, cun & 5,04 & 4,3 & 2,16836 & 11,46 \\
\hline 15 Terminalia cattapa & 4,32 & 4,3 & 13,7921 & 22,36 \\
\hline 16 Senna simea (Lam,) Irwindi \& Barneby & 2,16 & 3,2 & 3,56084 & 8,911 \\
\hline 17 Cordia subpubensens & 2,16 & 1,1 & 3,92925 & 7,151 \\
\hline 18 Bombax valletonii Hochr & 0,72 & 1,1 & 3,20135 & 4,985 \\
\hline 19 Zizipus jujubs Mill & 0,72 & 1,1 & 0,05041 & 1,834 \\
\hline 20 Nephelium $\mathrm{Sp}$ & 2,16 & 2,1 & 0,5361 & 4,822 \\
\hline 21 Tamarindus indica $\mathrm{L}$ & 0,72 & 1,1 & 0,96514 & 2,748 \\
\hline \multirow[t]{2}{*}{22 Amorphopalus $\mathrm{Sp}$} & 0,72 & 1,1 & 1,60435 & 3,388 \\
\hline & 100 & 100 & 100 & 300 \\
\hline
\end{tabular}

\subsection{Indeks Nilai Penting (INP)}

Berdasarkan Tabel 2. di atas dapat dilihat bahwa dari 25 plot pengamatan spesies yang memiliki indeks nilai penting tertinggi adalah Mangifera indica $\mathrm{L}$ (43,7\%), diikuti Psidium eugenia L (40,4\%), Bombax ceiba $(32,7 \%)$ dan Acer niveum $\mathrm{BL}(32,0 \%)$ sedangkan spesies yang lainnya memiliki INP di bawah $20 \%$.

Tabel 2. Indeks Nilai Penting (INP) tegakan pohon di Hutan Lindung Lapeom 
Menurut Indriyanto (2006) spesies-spesies yang paling dominan atau berkuasa adalah spesies yang memiliki indeks nilai Penting tertinggi atau yang paling besar. Dari data di atas menunjukkan bahwa Mangifera indica L., Psidium eugenia L merupakan spesies yang paling dominan di wilayah penelitian karena kedua spesies ini hadir di hampir semua plot pengamatan (Mangifera indica $\mathrm{L}$ hadir di 19 plot dan Psidium eugenia L hadir di 17 plot) sedangkan jenis yang paling jarang hadir adalah Amorphopalus Sp (INP: 3,4\% hadir di 1 plot), Tamarindus indica L (INP : 2,7\%, hadir di 1 Plot), Zizipus jujuba (INP 1,8\%, hadir di 1 plot) dan Jatropa Sp (INP 1,9\%, hadir di 1 plot).

Menurut Sundarapandian \& Swamy (2000) Indeks nilai penting merupakan salah satu parameter yang dapat memberikan gambaran tentang peranan jenis yang bersangkutan dalam komunitasnya atau pada lokasi penelitian. Ini menunjukkan bahwa spesies Mangifera indica L dan Psidium Eugenia L merupakan spesies yang memiliki peranan besar dalam kelanjutan ekosistem hutan lindung ini.

\subsection{Keanekaragaman Jenis Pohon}

Indeks keanekaragaman jenis pohon di hutan lindung Lapeom dapat dilihat secara detail di Tabel 3.

Tabel 3. Indeks Keanekaragaman jenis pohon di hutan lindung Lapeom

\begin{tabular}{|c|c|c|c|c|c|}
\hline No & Nama Jenis/Spesies & $\sum$ ind & $\mathrm{Pi}$ & $\mathrm{LnPi}$ & Pi LnPi \\
\hline 1 & Casuarina junghuniana Mia & 4 & 0,03 & $-3,5$ & $-0,1$ \\
\hline 2 & Ficus benjamina $\mathrm{L}$ & 5 & 0,04 & $-3,3$ & $-0,12$ \\
\hline 3 & Psidium Eugenia $\mathrm{L}$ & 17 & 0,12 & $-2,1$ & $-0,26$ \\
\hline 4 & Acer niveum $\mathrm{BL}$ & 19 & 0,14 & -2 & $-0,27$ \\
\hline 5 & Schleisera okosa Merr & 3 & 0,02 & $-3,8$ & $-0,08$ \\
\hline 6 & Bombax ceiba $\mathrm{L}$ & 17 & 0,12 & $-2,1$ & $-0,26$ \\
\hline 7 & Casia fistula $\mathrm{L}$ & 8 & 0,06 & $-2,9$ & $-0,16$ \\
\hline 8 & Alstonia scholaris $\mathrm{R}, \mathrm{Br}$ & 4 & 0,03 & $-3,5$ & $-0,1$ \\
\hline 9 & Jatropa $S p$ & 1 & 0,01 & $-4,9$ & $-0,04$ \\
\hline 10 & Anona reticulata $\mathrm{L}$ & 4 & 0,03 & $-3,5$ & $-0,1$ \\
\hline 11 & Mangifera indica $\mathrm{L}$ & 20 & 0,14 & $-1,9$ & $-0,28$ \\
\hline 12 & Timonius amboinicus Boerl & 5 & 0,04 & $-3,3$ & $-0,12$ \\
\hline 13 & Delonix regia (Bojer Ex Hook) Raf, & 6 & 0,04 & $-3,1$ & $-0,14$ \\
\hline 14 & Acasia auriculiaformis $\mathrm{A}$, cun & 7 & 0,05 & -3 & $-0,15$ \\
\hline 15 & Terminalia cattapa & 6 & 0,04 & $-3,1$ & $-0,14$ \\
\hline 16 & Senna simea, (Lam,) Irwindi \& Barneby & 3 & 0,02 & $-3,8$ & $-0,08$ \\
\hline 17 & Cordia subpubensens & 3 & 0,02 & $-3,8$ & $-0,08$ \\
\hline 18 & Bombax valletonii Hochr & 1 & 0,01 & $-4,9$ & $-0,04$ \\
\hline & Zizipus jujubs Mill & 1 & 0,01 & $-4,9$ & $-0,04$ \\
\hline 20 & Nephelium $\mathrm{Sp}$ & 3 & 0,02 & $-3,8$ & $-0,08$ \\
\hline & Tamarindus indica $\mathrm{L}$ & 1 & 0,01 & $-4,9$ & $-0,04$ \\
\hline & Amorphopalus Sp & 1 & 0,01 & $-4,9$ & $-0,04$ \\
\hline & & 139 & 1 & -78 & $-2,71$ \\
\hline & & & & \multicolumn{2}{|c|}{$\mathrm{H}=-(-2,7)$} \\
\hline & & & & \multicolumn{2}{|c|}{$\mathrm{H}=2,7$} \\
\hline
\end{tabular}

Berdasarkan data pada Tabel 3. tentang Indeks Keragaman dapat dilihat indeks keanekaragaman pohon di hutan lindung Lapeom bernilai 2.7. Magurran, (1988), mengatakan Kisaran nilai hasil perhitungan indeks keragaman $(\mathrm{H})$ sebagai berikut jika:

a. $\mathrm{H} \geq 3 \quad$ : Keragaman spesies tinggi

b. $1<\mathrm{H}<3$ : Keragaman spesies sedang

c. $\mathrm{H} \leq 1 \quad$ : Keragaman spesies rendah

Berdasarkan hasil penelitian dan kisaran indeks keanekaragaman pohon yang dikemukakan oleh magurran maka indeks keanekaragaman pohon di Hutan Lindung Lapeom masuk dalam kisaran kedua yaitu $1<\mathrm{H}<3$ yaitu kategori sedang dengan nilai 2,7. Setiap kisaran pada indeks keanekaragaman memiliki tolok ukur tersendiri. Pada penelitian ini hasil perhitungan indeks keanekaragaman (H') masuk dalam kategori sedang yang berarti keanekaragaman sedang, produktivitas cukup kondisi ekosistem cukup seimbang dan tekanan ekologis sedang. Dari tolok tersebut menunjukkan bahwa wilayah Hutan Lindung Lapeom memiliki tingkat produktivitas pohon yang cukup, kondisi ekosistem yang cukup seimbang dan memiliki tekanan ekologis yang sedang.

\section{Simpulan}

Secara keseluruhan, dalam penelitian ini ditemukan 22 jenis pohon yang tersebar dalam 17 famili. Famili (suku) yang memiliki jumlah spesies terbanyak adalah famili Caesalpinaceae sebanyak 4 spesies yakni Cassia fistula L., Delonix regia (Bojer ex Hook.)Raf., Senna simea (Lam.) Irwindi \& Barneby., dan Tamarindus indica L. Jenis yang paling banyak jumlah individunya adalah Mangifera indica L dari famili Anacardiaceae sebanyak 20 individu. Spesies yang memiliki indeks nilai penting tertinggi adalah Mangifera indica L (43, 7\%), sedangkan jenis yang memiliki indeks nilai penting terendah adalah Zizipus jujuba $(1.8 \%$,) dan Indeks Keanekaragaman jenis pohon di hutan lindung Lapeom termasuk kategori sedang dengan nilai bernilai 2.7. Indeks keragaman tumbuhan tingkat pohon hutan lindung Lapeom termasuk kategori sedang yang berarti wilayah Hutan Lindung Lapeom memiliki tingkat produktivitas pohon yang cukup, kondisi ekosistem yang cukup seimbang dan memiliki tekanan ekologis yang sedang.

\section{Pustaka}

Arief, A. 2001. Hutan \& kehutanan. Kanisius.

Gopal, B. \& Bhardwaj, N. 1979. Elements of Ecology. Vikas.

Hardjosuwarno, S. 1990. Dasar-dasar Ekologi Tumbuhan. Yogyakarta: Fakultas Biologi UGM.

Indriyanto 2006. Ekologi hutan. Bumi Aksara.

Kusmana, C. 1997. Ekologi dan Sumberdaya Ekosistem Mangrove. Bogor. Jurusan Manajemen Hutan Fakultas Kehutanan IPB.

Magurran, A.E. 1988. Why diversity? Ecological diversity and its measurement. Springer, hlm.1-5.

Mueller-Dombois, D. \& Ellenberg, H. 1974. Aims and Methods of Vegetation Ecology. Wiley.

Setiadi, D. \& Tjondronegoro, P. 1989. Dasar-dasar ekologi. Departemen Pendidikan dan Kebudayaan. Direktorat Jenderal Pendidikan Tinggi-PAU Hayati Institut Pertanian Bogor.

Soegianto, A. 1994. Ekologi Kuantitatif: Metode analisis populasi dan komunitas. Surabaya: Usaha Nasional.

Stiling, P. 2014. Ecology.

Sulistyawati, E., Rosleine, D. \& Sungkar, R. 2005. Struktur komunitas dan keanekaragaman tumbuhan di G. Papandayan. Struktur komunitas dan keanekaragaman tumbuhan di G. Papandayan. Paper presented on Seminar Penggalang Taksonomi Tumbuhan Indonesia. Universitas Pendidikan Indonesia, Bandung. hlm.18-19.

Sundarapandian, S. \& Swamy, P. 2000. Forest ecosystem structure and composition along an altitudinal gradient in the Western Ghats, South India. Journal of Tropical Forest Science, 104-123.

TTU, B.P.S. 2007. Timor Tengah Utara Dalam Angka. BPS TTU. Kefamenanu. 